\title{
Corn and Rice Bran Biodiesel Blend as Alternative Fuels for Diesel Engine at Different Injection Pressures
}

\author{
Nanjundaiah $^{1}$, Ramesha D.K ${ }^{2}$ \\ ${ }^{1}$ Research Scholar, Mechanical Engineering, UVCE, Bangaluru. \\ ${ }^{2}$ Associate Professor, Mechanical Engineering, UVCE, Bangaluru.
}

\begin{abstract}
Experimental study has been carried out using methyl esters of corn oil and rice branoilas fuel blend at the most recommended blending ratio of $20 \%$ biodiesel with conventional diesel fuel as alternative fuel for dieselengine. The effect of fuel injection pressure on diesel engine performance using B20 blend in comparison with that using neat diesel fuel is studied. Preliminary experiments regarding the analysis of fuel properties indicate that oils are heated up to the temperature of $50-60{ }^{\circ} \mathrm{C}$ during process of transesterification. This is necessary to reduce high viscosity of oils as compared with that of neat diesel fuel. A series of tests were conducted on four-stroke single cylinder air cooled direct injection (DI) diesel engine at constant engine speed with varying load in percentage such as 0,25,50,75 and 100and varying injection pressures of 180, 200 and 200 bar respectively. The investigating parameters include the engine performance parameters such as brake thermal efficiency, brake specific fuel consumption, combustion and emission parameters. The properties of methyl esters of corn oil and rice bran oil fuel blend affect the fuel injection system and cause an increase in the duration of fuel injection. This may cover more time according to the increase in the amount of injected fuel necessary to overcome the power loss accompanied with the biodiesel low energy content. The major conclusion is that, the increased injection pressure gives better results regarding the engine performance parameters in comparison with case of the original injection pressure for all tested fuels, thus the best results are obtained at high injection pressure of 200 bar. At this conditions it is concluded that, the increase of engine BTE and the decrease of BSFC was observed. The emissions like UBHC, CO are comparatively lower for biodiesel blend of $B 20$ compared with diesel fuel. The heat release rate (HRR) and peak pressure $(P-\theta)$ are higher for both tested fuels. This is due to better combustion of fuel due to presence of oxygen in biodiesel. But NOx and smoke opacity are marginally higher than that of the diesel fuel.
\end{abstract}

Keywords: Diesel engine, Methyl esters of oil, Injection pressure, Engine performance, Combustion and emission parameters.

\section{Introduction}

Diesel engines have been received a great attention due to their high power performance, the thermal efficiency and low emissions in comparison with gasoline and other engines. This sector of transportation system consumes a large portion of non-renewable petroleum fuels. Thus it is urgent to look for a renewable fuel resource that will replace (or at least reduce consumption of) traditional fuels. One of promising resource is the production of the biodiesel from vegetable oils [1].The ASTM (American Society for Testing and Materials Standard) describes the biodiesel as esters monoalkyl of fatty acids of long chain that are produced from vegetable oil, animal fat or waste cooking oils in a chemical reaction known as trans esterification [2]. Transesterified vegetable oil (biodiesel) has recently attracted enormous attention all over the world as an alternative fuel for diesel engines because of its renewability. Biodiesel can be produced from renewable sources such as vegetable oil, animal fat and used cooking oil. Currently, the cost of biodiesel is high as compared to conventional diesel oil because most of the biodiesel is produced from pure vegetable oil [3].

The physical properties of the biodiesel fuel such as viscosity, volatility and flash point affect the different processes occurring within the diesel engine cylinder; fuel atomization, fuel evaporation, fuel mixing with air and fuel burning and thereby engine performance. The injection pressure plays an importantrole in metering the desired amount of fuel at correct time depending on engine operating conditions. For diesel engine, direct injection fuel system is used to achieve a high degree of atomization in orderto enable sufficient fuel evaporation in short timeeffectively with air and so enhance the combustion process. The fuel injection process is influenced not only by the fuel properties,but also by the fuel injection construction system (number and dimensions of nozzles), and sufficient spray penetration in order to mix fuel, the correct injection timing and the injection operating conditions [4]. 


\section{Nomenclature}

\begin{tabular}{|l|l|}
\hline COME & Corn Oil Methyl Ester \\
\hline ROME & Rice bran Oil Methyl Ester \\
\hline ASTM & American Society For Testing and Materials \\
\hline BSFC & Brake Specific Fuel Consumption \\
\hline BTE & Brake Thermal Efficiency \\
\hline CI & Compression Ignition \\
\hline BTU & British Thermal Unit \\
\hline CO & Carbon Monoxide \\
\hline Cst & Centistokes \\
\hline NOx & Oxides of Nitrogen \\
\hline FAME & Fatty Acid Methyl Ester \\
\hline PPM & Parts Per Million \\
\hline UBHC & Unburnt hydrocarbon \\
\hline${ }^{0}$ C & Degree Celsius \\
\hline
\end{tabular}

\section{Properties of Vegetable Oils Used}

The properties of biodiesel are very close to the mineral diesel. Therefore, biodiesel becomes a strong alternative to replace the diesel fuel. The attractive characteristics of biodiesel include higher cetane number, non-toxic emissions, and bio-degradability, absence of Sulphur and aromatic compounds and excellent lubricity. Biodiesel has higher viscosity than mineral diesel fuel. These vegetable oil esters contain 10-11\% oxygen by weight which may enhance combustion than hydrocarbon-based diesel fuel in an engine. Its cloud point and pour point are $15-25^{\circ}$ Chigher than that of the diesel fuel $[6,7,8]$.

Most fatty acids, vegetable oils and fatty acid esters, especially those with long carbon chains, all components have pure physical properties. In this study, fatty acids and their corresponding methyl esters, and vegetable oils and their respective biodiesels are considered.

Table 1: Fatty acid composition of Rice bran oil and Corn oil [1,4]

\begin{tabular}{|l|l|l|}
\hline & \multicolumn{1}{|l|}{ Rice Bran Oil } & \multicolumn{1}{l|}{ Corn Oil } \\
\hline Fatty Acid & Percentage & 0.1 \\
\hline C14:0 Myristic acid & 0.112 & 8.1 \\
\hline C16:0 Palmitic acid & 14.991 & 2.5 \\
\hline C18:0 Stearic acid & 1.288 & 30.1 \\
\hline C18:1 Oleic acid & 41.513 & 28.2 \\
\hline C18:2 Linoleic acid & 38.562 & 1.7 \\
\hline C18:3 $\alpha$-Linoleic acid & 1.416 & \\
\hline
\end{tabular}

Table 2: Properties of Biodiesel and Diesel $[1,4,5]$

\begin{tabular}{|l|l|l|l|l|l|l|}
\hline Characteristics of oils & \multicolumn{2}{|l|}{ Raw oils } & \multicolumn{1}{|l|}{ Methyl Esters of oil } & \multicolumn{3}{c|}{ ASTM D } \\
\hline & Rice bran & Corn & Rice bran & Corn & Diesel & $6751-02$ \\
\hline Specific gravity at $30^{0} \mathrm{C}$ & 0.906 & 0.925 & 0.885 & 0.869 & 0.841 & $0.87-0.89$ \\
\hline Viscosity $(\mathrm{Cst})$ at $40^{\circ} \mathrm{C}$ & 38 & 44 & 4.54 & 8.5 & 4.52 & $1.9-6.0$ \\
\hline Flash point $\left({ }^{\circ} \mathrm{C}\right)$ & 184 & 310 & 162.8 & 158 & 66 & 130 \\
\hline Fire point $\left({ }^{0} \mathrm{C}\right)$ & 337 & 332 & 194 & 163 & 78 & 183 \\
\hline Cloud point $\left({ }^{\circ} \mathrm{C}\right)$ & 13 & 11 & 9 & 7 & 6 & 2 \\
\hline Pour point $\left({ }^{\circ} \mathrm{C}\right)$ & 1 & 0.95 & -2 & -1.5 & -7 & -6 \\
\hline Heating value $(\mathrm{MJ} / \mathrm{kg})$ & 41.1 & 38.3 & 41.3 & 39.82 & 42 & 37.518 \\
\hline Cetane number & 51 & 48 & 57 & 52 & 45 & $47 \mathrm{~min}$. \\
\hline Carbon residue $(\%, \mathrm{w} / \mathrm{w})$ & 0.6 & 0.49 & 0.35 & 0.265 & 0.1 & 0.3 \\
\hline
\end{tabular}

\section{1: Objectives}

\section{Objectives and Methodology}

The following objectives were drawn for the work:

* To study and compare the properties of oils used, methyl esters with diesel fuel to fulfill the ASTM standards.

* To run a diesel engine using methyl esters of corn oil (COME) and rice bran oil (ROME) for the blend of $\mathrm{B} 20$ in order to evaluate their performance in regard to BP, BTE, BSFC and emissions like $\mathrm{NO}_{\mathrm{x}}$, UBHC, $\mathrm{CO}$ and Smoke opacity and combustion characteristics.

* Diesel engine was running by using methyl esters of corn oil (COME) and rice bran oil (ROME) and its blend B20 with diesel fuel at injection pressure 180, 200 and 220 bar respectively for the purpose of optimising the injection pressure to achieve better performance. 


\section{2: Methodology:}

To achieve the above mentioned objectives, following methodology is adapted and followed so as to get the accurate and reliable results.

- Experiments are conducted at No load, 25\%, 50\%, 75\% and 100\% respectively of full load condition with B20 methyl esters of corn oil (COME) and rice bran oil (ROME).

* Experiments are conducted with B20 methyl esters and diesel at the designed injector opening pressure of $180 \mathrm{bar}$ and injection angle of $27^{\circ} \mathrm{bTDC}$ and studied the performance, combustion and emission characteristics.

* Similar experiments are conducted at 200 bar and 220 bar injector opening pressure with B20 methyl esters to optimize injection pressure.

* Performance, combustion and emission parameters are tabulated and plotted and compared with diesel fuel performance, and the conclusions are drawn based on the results obtained.

\section{1: Introduction}

\section{Results and Discussion}

Experiments were conducted at three different injection pressure Viz., 180 bar, 200 bar and 220 bar respectively for COME and ROME to study the effect of injection pressure on engine performance, combustion and emission characteristics. The results obtained with diesel fuel at 180 bar injection pressure are taken as base-line data for comparison with methyl esters of oils at three different injection pressure and the results are shown in Figures 4.1 to 4.18.

\subsection{1: Brake Thermal Efficiency (BTE):}

Figures 4.1 and 4.2 shows the variation of BTE with load at three different injection pressure at optimum blend B20 for COME and ROME compared with diesel fuel of 180 bar injection pressure. BTE increases with increasing in load for all the tested fuels. This is due to reduction in heat loss with increase in load (9).

Figure 4.3 shows the variation of BTE with injection pressure for COME and ROME at full load. For COME and ROME, BTE is low for injection pressure of 180 bar. This is due to the coarse spray formation and poor atomization of the injected fuel. By increasing the injection pressure (200 bar), BTE of both COME and ROME fuels has improved considerably. This may be due to the reduction in the viscosity, improved atomization and better combustion. BTE is decreased for further increasing of injection pressure (220 bar). This is due to higher injection pressure leads a very fine fuel spray in to the combustion chamber, due to this, penetration of fuel spray reduce the momentum of the fuel droplet will reduce which might increase the delay period in the combustion. The optimum value of BTE for COME and ROME was found at 200 bar $(9,10)$.

\subsection{2: Brake Specific Fuel Consumption (BSFC):}

Figures 4.4 and 4.5 shows the variation of BSFC with load at three different injection pressure at optimum blend B20 for COME and ROME compared with diesel fuel at 180 bar injection pressure. BSFC for COME and ROME at optimum injection pressure 200 bar is marginally higher than that of diesel fuel at lower loads. This may be attributed to the fact that biodiesels have lower calorific value, $10 \%$ lower energy content on mass base and so a greater volume of fuel shall be injected to maintain engine power and higher density. Again at optimum injection pressure of 200 bar and at higher loads, the BSFC of COME and ROME is marginally lower than the diesel fuel. This is due to the presence of oxygen in biodiesel whichcontribute more complete combustion.

Figure 4.6 shows the variation of BSFC with injection pressure for COME and ROME at full load. BSFC has decreased with increase in injection pressure. This is due to that as injection pressure increases, the penetration length and spray cone angle increases, so that at optimum injection pressure 200 bar, air-fuel mixing and spray atomization will be improved. It can be seen that the lowest value of BSFC for the tested fuels was found to be at 200 bar injection pressure $(10,11,12)$.

\subsection{3: Unburnt Hydro Carbon (UBHC) emission:}

Figures 4.7 and 4.8 shows the variation of Unburnt Hydrocarbon emission (UBHC) with load for COME and ROME at three different injection pressure and at optimum blend B20 compared with diesel fuel of 180 bar injection pressure. Unburnt hydrocarbons are the result of incomplete combustion of the fuel. For all the tested fuels, UBHC emission increases under all the loading conditions. UBHC emissions are higher in the diesel fuel for all the loading conditions because of presence of heavier hydrocarbon particles $(12,13)$.

Figure 4.9 shows the variation of UBHC emission with injection pressure for COME and ROME at full load. UBHC emissions decrease with increase in injection pressure from 180 bar to 200 bar. For further increase of injection pressure to $220 \mathrm{bar}$, increasing trend in UBHC emission this is because of finer fuel spray 
which reduces the momentum of the fuel droplet resulting in partial combustion of the fuel. Lowest value of UBHC emission for the optimum pressure of 200 bar.

\subsection{4: Carbon Monoxide (CO) emission:}

Figures 4.10 and 4.11 shows the variation of $\mathrm{CO}$ emissions with load for COME and ROME at three different injection pressure and at optimum blend B20 compared with diesel at 180 bar. The CO emission increases for all the tested fuels and under all the loading conditions.

From the Figures 4.10 and 4.11, it can be seen that the CO emission of diesel is more than that of the methyl esters of oil. This is due to biodiesel is an oxygenated fuel and that itself contains more than $11 \%$ of oxygen which helps in more complete combustion of the fuel hence $\mathrm{CO}$ emission is reduced in the exhaust. The $\mathrm{CO}$ emission is lower at part load and shows an increasing trend with load and is maximum at full load for all the tested fuels. This is common in I.C. engines since air-fuel ratio decreases with increase in load. The CO emission increases as air-fuel ratio becomes greater than stoichiometric value.

Figure 4.12 shows the variation of $\mathrm{CO}$ emission with injection pressure for COME and ROME at full load. CO emission is reduced with increase in injection pressure to $200 \mathrm{bar}$ from the rated injection pressure of 180 bar. It can also be seen that as the injection pressure is further increased to 220 bar there seems to be an increasing trend in $\mathrm{CO}$ emission. This is because of incomplete combustion of the injected fuel resulting in higher unburnt hydrocarbons. It can be note that, the lowest value of $\mathrm{CO}$ emission for both fuels tested is found to be at 200 bar injection pressure $(14,15)$.

\subsection{5: Oxides of Nitrogen (NOx) emission:}

Figures 4.13 and 4.14 shows the variation of oxides of nitrogen emission with load at three different injection pressure and at optimum blend B20 for COME and ROME as compared with the diesel fuel of 180 bar.

Figure 4.15 shows the variation of nitrogen oxide emission with injection pressure for the methyl esters of corn oil and rice bran oil at full load. Figure shows the lower NOxemission at the injection pressure 200 bar, this may be due to the decrease in the engine exhaust temperature. Higher the NOx emission at the injection pressure 180 bar and 220 bar respectively due to the increase in the engine exhaust temperature $(16,17,18)$.

\subsection{6: smoke opacity emission:}

Figures 4.16 and 4.17 shows the variation of smoke opacity emission with the load at three different injection pressure and at optimum blend B20 for COME and ROME compared with diesel fuel of 180 bar. Smoke is mainly produced in the diffuse combustion phase; Smoke opacity increases with all tested fuels under all the loading conditions. Smoke opacity is quietly lower for the biodiesel blend compared to diesel fuel. The lack of heavy petroleum oil residues in the vegetable oil esters that are normally found in the diesel fuel is the reason for less smoke. Since the biodiesel contains more than $11 \%$ of oxygen, there is an increased efficiency of combustion even for the petroleum fraction of the blend. The oxygenated fuel blend lead to an improvement in diffuse combustion for the optimum blend of B20. The biodiesel has lower $\mathrm{C} / \mathrm{H}$ ratio and absence of aromatic compounds $(17,18)$.

Figure 4.18 shows the variation of smoke opacity emission with injection pressure for COME and ROME at full load. From the figure it can be observed that with increase in injection pressure from 180 bar to 200 bar at full load and the smoke opacity has reduced for both COME and ROME. Further, the higher smoke opacity has been recorded at injection pressure of 220 bar $(19,20)$.

\subsection{7: Summary}

* Methyl ester of neat vegetable oil and their blend with diesel fuel yield better performance and emission characteristics.

- BTE of biodiesel increases substantially with load for different injection pressure compared to diesel fuel. This is due to the reduction in the viscosity, improved atomization, better spray characteristics and better fuel combustion etc.

* BSFC of biodiesel is marginally higher than that of diesel fuel. This may be attributed to the fact that biodiesels have lower calorific value and higher viscosity.

- BSFC has decreased with increase in injection pressure for all the fuels and under all the loading conditions.

* The UBHC emission increases with increasing in load for all the fuels and increased with concentration percentage increase in biodiesel-diesel blend.

- At B20 blend for COME and ROME, lower the UBHC emission than that of the diesel fuel. This is due to the higher cetane number of the biodiesel, resulting in more complete combustion in the engine cylinder.

* The increasing trend of $\mathrm{CO}$ emission is due to increase in fuel consumption and knock with the engine power output. 
* Low density and viscosity of the methyl esters of oil; increase the rate of evaporation of the fuel and specific fuel consumption increases as the mass of the fuel consumed per kw power developed per hour increases.

* The NOx emissions for the COME and ROME is varies linearly with the load as compared with the diesel fuel.

* The biodiesel-fueled engines produce less carbon monoxide, unburned hydrocarbon, and smoke emissions compared to diesel fuel but higher NOx emissions.

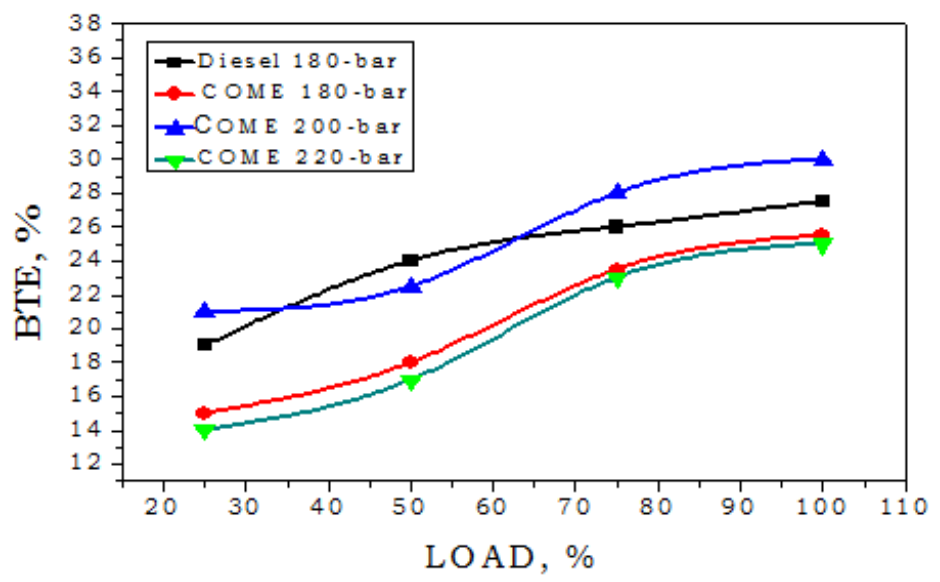

Figure 4.1: Variation of BTE with Load for COME at different injection pressure.

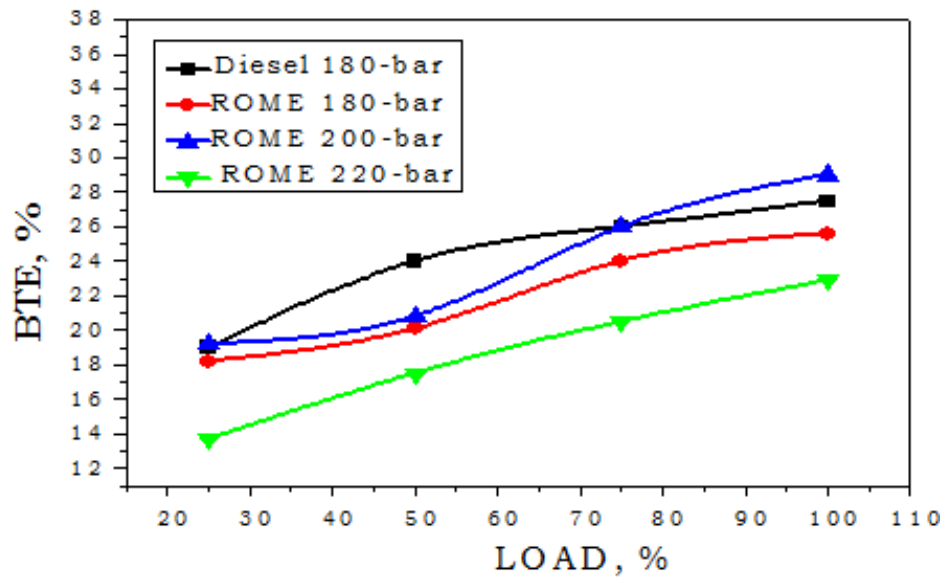

Figure 4.2: Variation of BTE with Load for ROME at different injection pressure

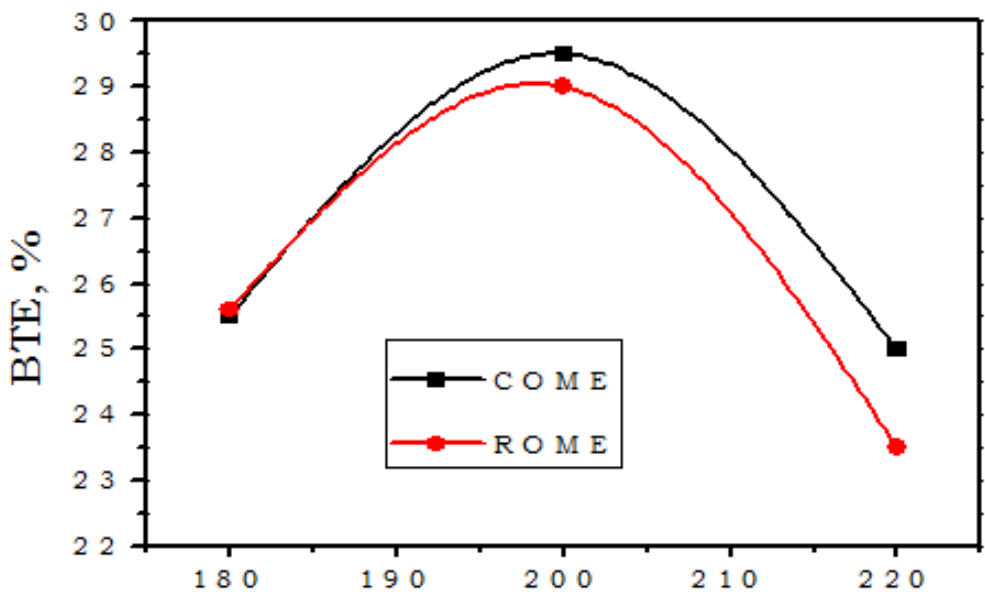

Injection Pressure, bar

Figure 4.3: Variation of BTE with injection pressure for COME and ROME at full load. 


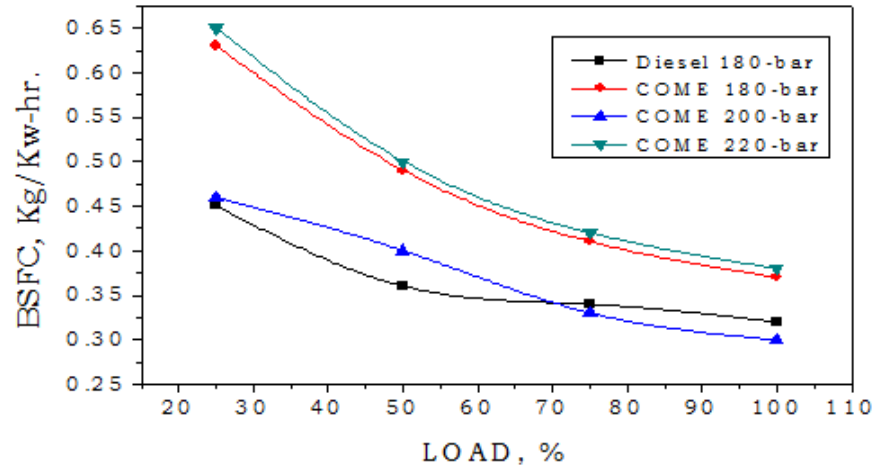

Figure 4.4: Variation of BSFC with Load for COME at different injection pressure.

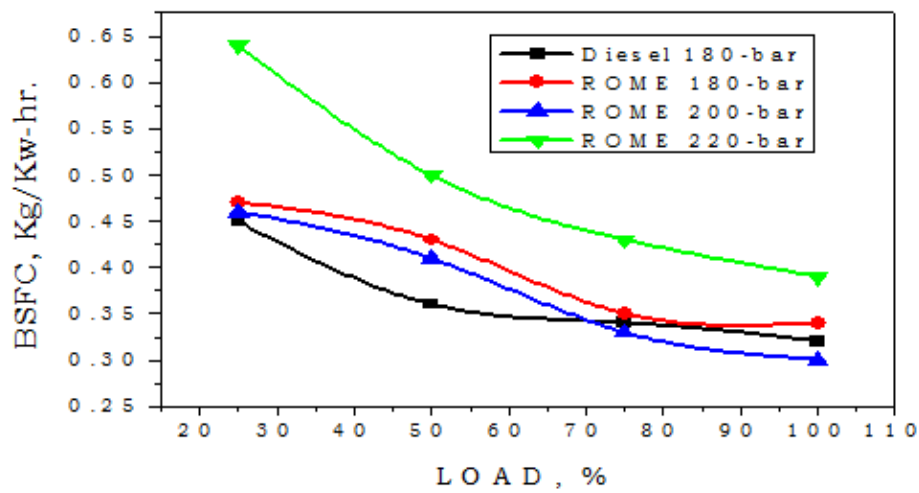

Figure 4.5: Variation of BSFC with Load for ROME at different injection pressure

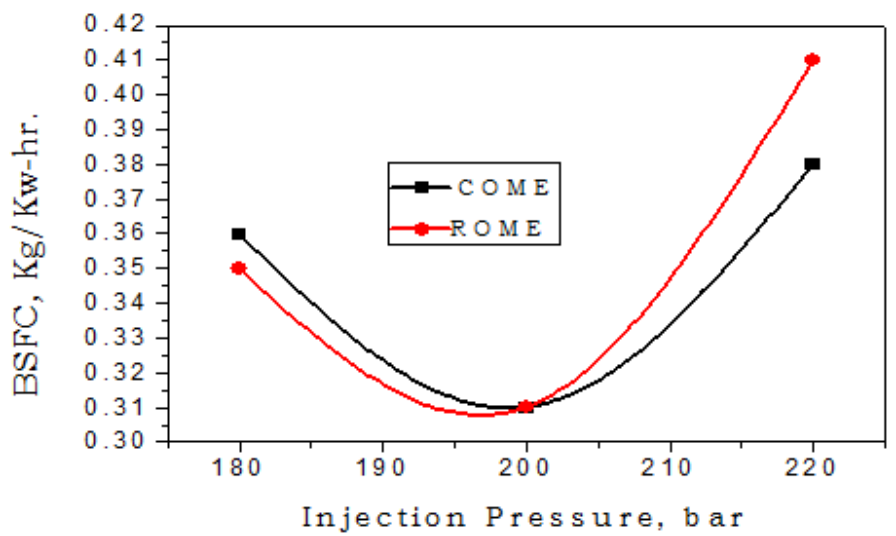

Figure 4.6: Variation of BSFC with injection pressure for COME and ROME at full load.

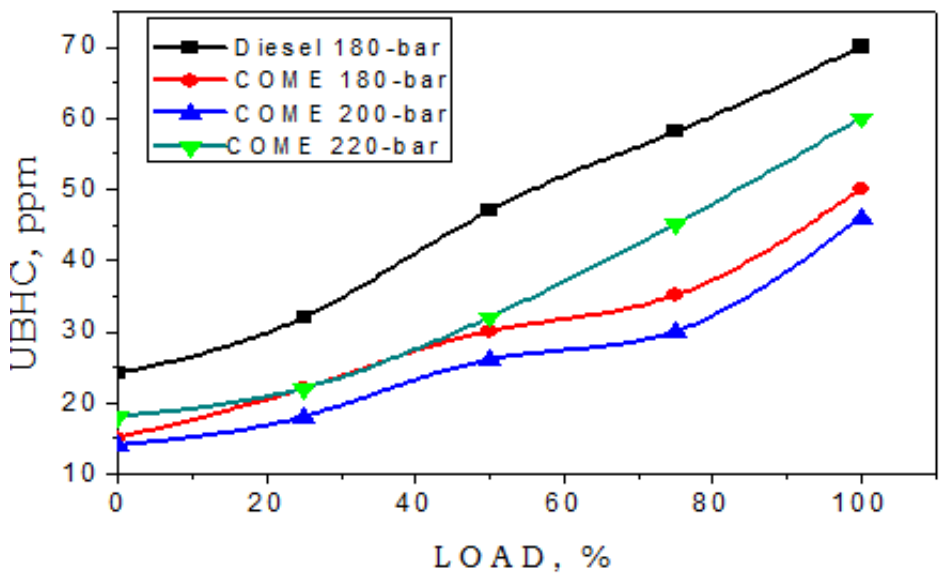

Figure 4.7: Variation of UBHC emission with load for COME at different injection pressure. 


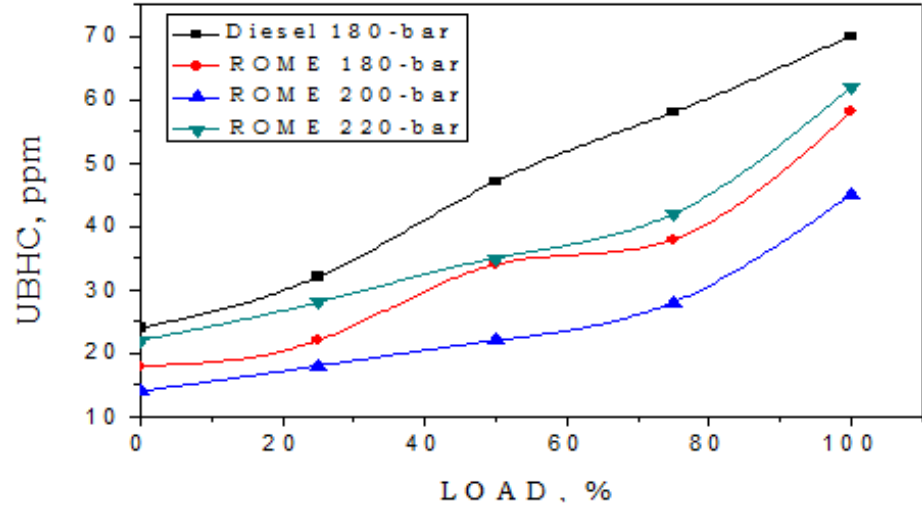

Figure 4.8: Variation of UBHC emission with load for ROME at different injection pressure.

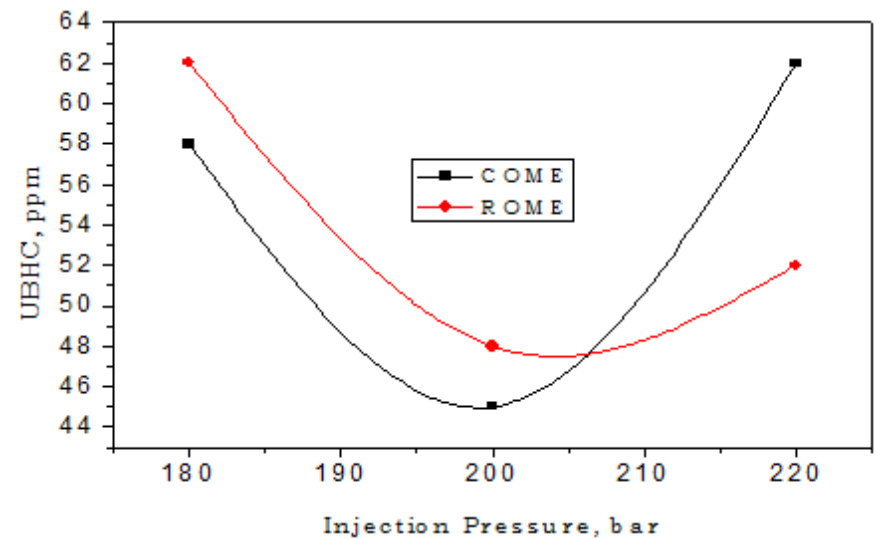

Figure 4.9: Variation of UBHC emission with injection pressure for COME and ROME at full load.

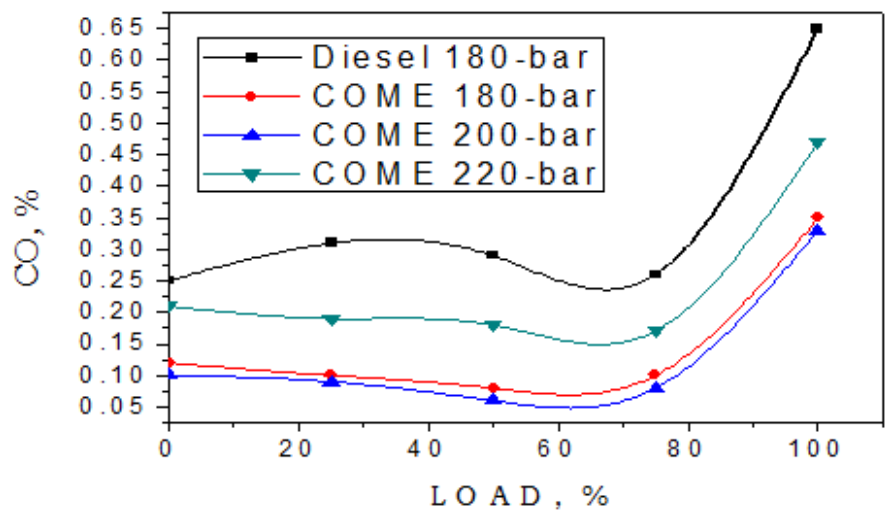

Figure 4.10: Variation of $\mathrm{CO}$ emission with load for $\mathrm{COME}$ at different injection Pressure.

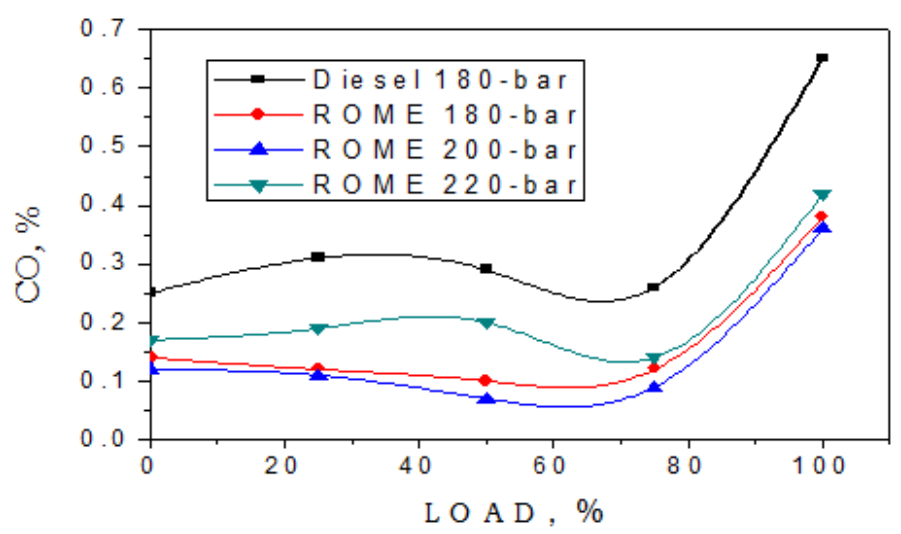

Figure 4.11: Variation of $\mathrm{CO}$ emission with load for ROME at various injection pressure. 


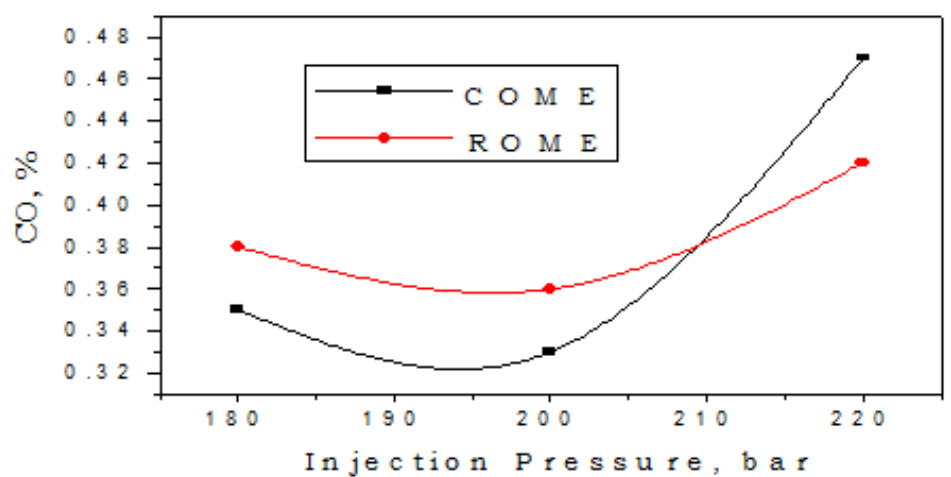

Figure 4.12: Variation of $\mathrm{CO}$ emission with injection pressure for COME and ROME at full load.

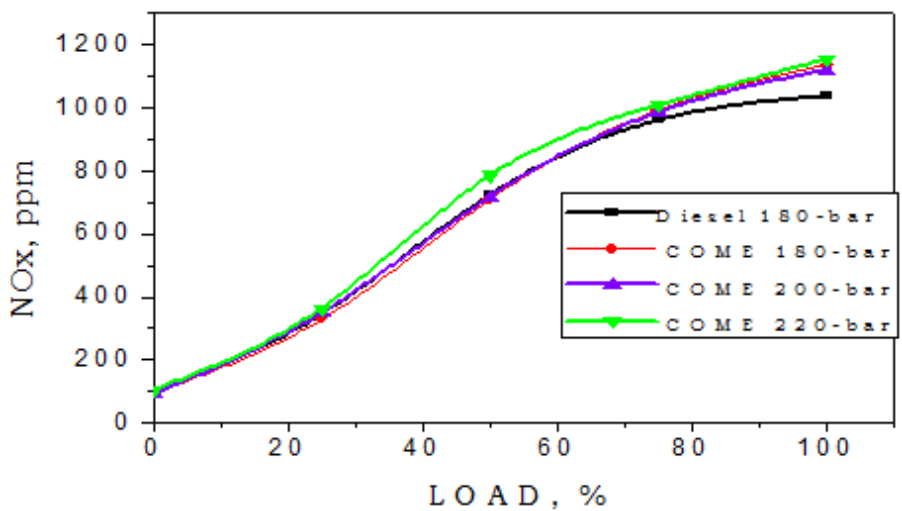

Figure 4.13: Variation of NOx emission with load for COME at different injection pressure.

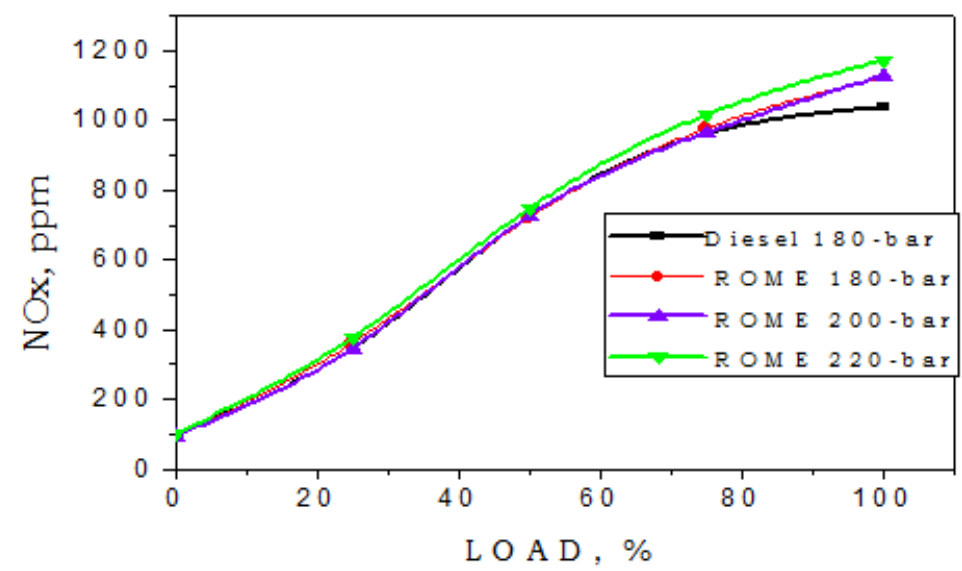

Figure 4.14: Variation of NOx emission with load for ROME at different injection pressure

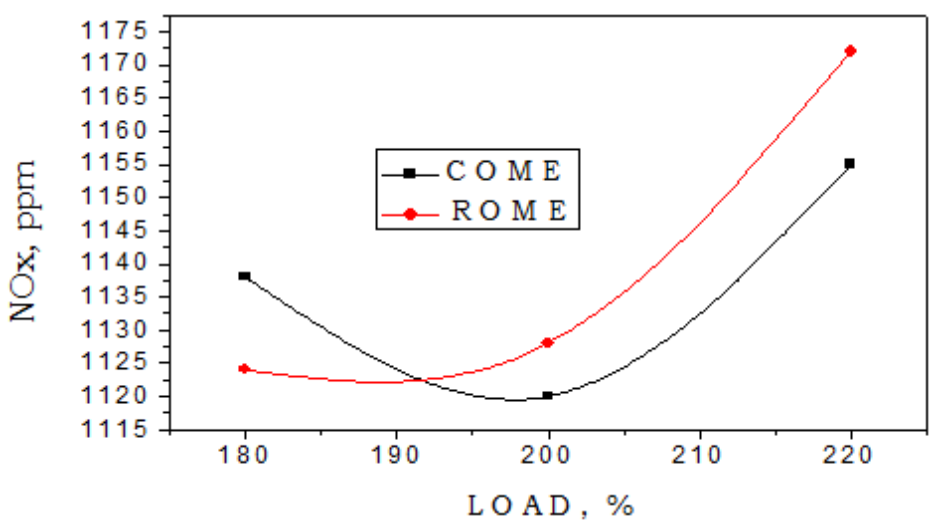

Figure 4.15: Variation of NOx emission with injection pressure for COME and ROME at full load. 


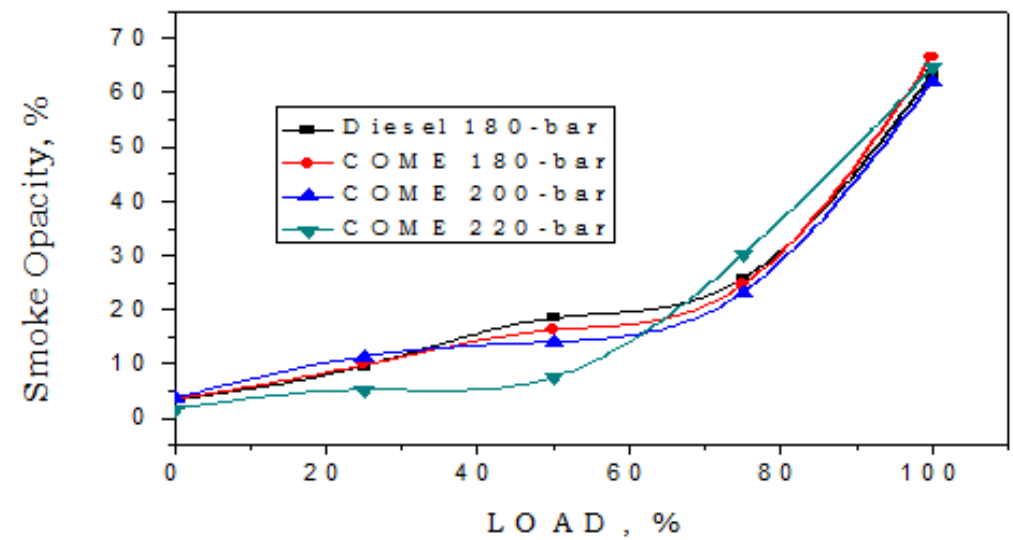

Figure 4.16: Variation of Smoke opacity emission with load for COME at different injection pressure.

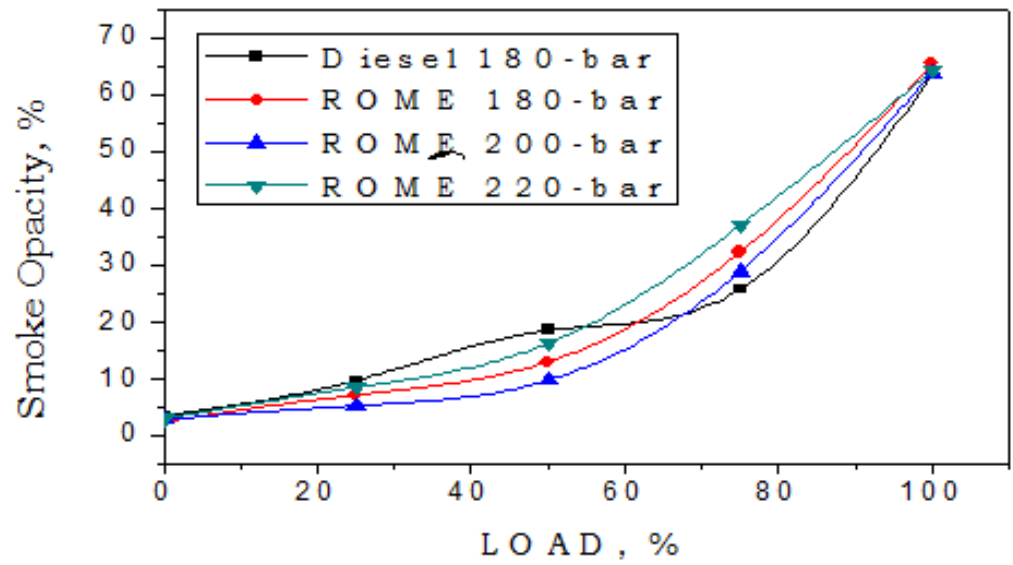

Figure 4.17: Variation of Smoke opacity emission with load for ROME at different injection pressure.

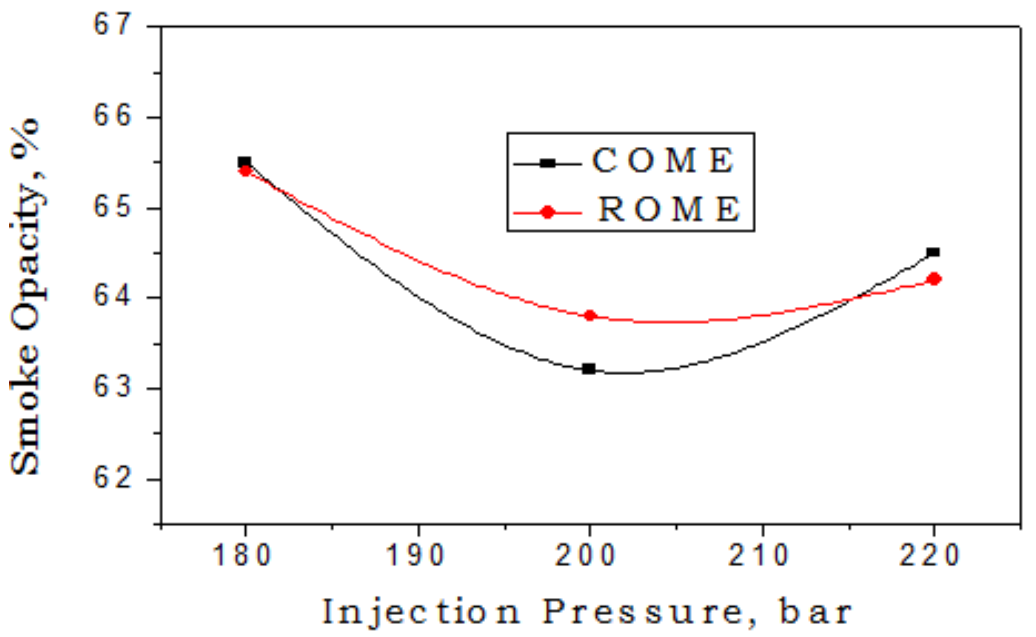

Figure 4.18: Variation of Smoke opacity emission with injection pressure for COME and ROME at full load .

\section{References}

[1]. M.S. Shehata, Ali Attia, S.M. Abdel Razek, "Corn and soybean biodiesel blends as alternative fuels for diesel engine at different injection pressures", Fuel, Volume 161, 2015, Pages: 49 - 58.

[2]. Carlos A. Guerrero F., Andrés Guerrero-Romero and Fabio E. Sierra, "Biodiesel Production from Waste Cooking Oil", BiodieselFeedstocks and Processing Technologies, National University of Colombia, Colombia.

[3]. M.C Math, SudheerPrem Kumar, Soma V. Chetty, "Technologies for biodiesel production from used cooking oil - A review", Energy for sustainable Development, Volume 14, 2010, Pages: 339-345.

[4]. Emmanuel I, Bello and Oluwole O. Oluboba, "Rice Bran Oil Biodiesel”, European Journal of Engineering and Technology, Volume 2, Issue 2, 2014, Pages: $59-69$.

[5]. F. AYDIN, "The Basic Properties of Transesterified Corn Oil and Biodiesel-Diesel Blends", Energy Sources, Taylor and Francis Group, Volume 33, December 2011, Pages: 745 - 751. 
Corn and Rice Bran Biodiesel Blend as Alternative Fuels for Diesel Engine at Different Injection...

[6]. H. An, W.M. Yang, A. Maghbouli, S.K. Chou, K.J. Chua, "Detailed physical properties prediction of pure methyl esters for biodiesel combustionmodelling”Applied Energy, National University of Singapore, Volume 102, 2103, Pages:647-656.

[7]. B.M.Gitte, SayyedSiraj, H.M.Dharmadhikari, "Performance and emission characteristics of diesel engine fuelled with biodiesel and its blends: A review",International Journal of Engineering Research and Technology, Volume 2, Issue 10, October 2013, Pages: $3235-3243$

[8]. Evangelos G. Giakoumis, "A statistical investigation of biodiesel physical and chemical properties, and their correlation with the degree of unsaturation”, Renewable Energy, National Technical University of Athens, Athens, Greece, Volume 50, 2013, Pages: $858-878$.

[9]. JinlinXue, Tony E. grift, Alan Hansen, "Effect of biodiesel on engine performances and emissions", Renewable and Sustainable Energy Reviews, Volume 15, 2011, Pages: 1098 - 1116.

[10]. K.NanthaGopal, Arindam Pal, Sumit Sharma, CharanSamanchi, K. Sathyanarayana, T. Elango, "Investigation of emissions and combustion characteristics of a CI engine fuelled with waste cooking oil methyl ester and diesel blends", Alexandria Engineering Journal, production and hosting by Elsevier, Volume 53, November 2014, Pages: 281 - 287.

[11]. Avinash Kumar Agarwal, "Biofuels (alcohols and biodiesel) applications as fuels for internal combustion engines", Progress in Energy and Combustion Science, Volume 33, 2007, Pages: 233 - 271.

[12]. Robert O. Dunn, "Effects of minor constituents on cold flow properties and performance of biodiesel", Progress in Energy and Combustion Science, Volume 35, 2009, Pages: 481 - 489.

[13]. BhabaniPrasannaPattanaik, Basanta Kumar Nanda and Probir Kumar Bose, "Performance and emission studies on a single cylinder diesel engine fueled with diesel and rice bran oil methyl ester blends", International Journal of Advances in Engineering and Technology, Volume 3, Issue 1, March 2012, Pages: 505 - 513.

[14]. . .Emmanuel I. Bello and OluwoleOluboba, "Effects of blending rice bran oil biodiesel with diesel fuel on the properties of", Journal of Advances in Biotechnology, Volume 3, Issue1, April 2014, Pages:135 - 146

[15]. A.P. Sathiyagnanam, Member, IAENG and C.G. Saravanan, "Experimental Studies on the Combustion Characteristics and Performance of A Direct Injection Engine Fueled with Biodiesel/Diesel Blends with SCR", Proceedings of the World Congress on Engineering, VolIII, July 6 - 8, 2011, London, U.K.

[16]. A. E. Pillay, "Engine Emissions and Performances with Alternative Biodiesels: A Review", Journal of Sustainable Development, Volume 5, Issue 4, April 2012, Pages: 59-74.

[17]. .R.Mishra, C. Zhang, F. Gu, A.D.Ball, "Combustion and Performance Characteristics of CI Engine Running with Biodiesel", Energy, Volume 51, Issue 1, November 2013, Pages:101-115.

[18]. S.M. Palash, M.A. Kalam, H.H. Masjuki, B.M. Masum, "Impacts of biodiesel combustion on NOx emissions and their reduction approaches", Renewable and Sustainable Energy Reviews, Volume 23, 2013, Pages: 473 - 490.

[19]. U. Santhan Kumar, K. Ravi Kumar " Performance, Combustion and Emission Characteristics of Corn oil blended with Diesel", International Journal of Engineering Trends and Technology, Volume 4, Issue 9, September 2013, Pages: 3904-3910.

[20]. B. Tesfa, R. Mishra, C. Zhang, F. Gu, A.D.Ball, "Combustion and Performance Characteristics of CI Engine Running with Biodiesel", Springer, 2013 